\title{
KESANTUNAN BERBAHASA DALAM DISKUSI PADA ACARA INDONESIA LAWYERS CLUB DI TV ONE
}

\author{
${ }^{1}$ Diansyah Ramadhan, ${ }^{2}$ Ngudining Rahayu, ${ }^{8}$ Bambang Djunaidi \\ ${ }^{1,23}$ Universitas Bengkulu
}

Korespondensi: jikifla4@gmail.com

\begin{abstract}
Abstrak
Tujuan penelitian ini untuk mendeskripsikan pematuhan prinsip kesantunan berbahasa berdasarkan maksim kebijaksanaan, maksim kedermawanan, maksim penghargaan, maksim kesederhanaan, maksim pemufakatan, dan maksim kesimpatian. Metode yang digunakan dalam penelitian ini adalah metode deskriptif. Teknik pengumpulan data dalam penelitin ini teknik dokumentasi. Data dalam penelitian ini adalah tuturan yang mengandung kesantunan berbahasa yakni maksim kebijaksanaan, maksim kedermawanan, maksim penghargaan, maksim kesederhanaan, maksim pemufakatan, dan maksim kesimpatian dalam acara diskusi ILC di TV One tayang pada tanggal 09 Maret 2019-26 maret 2019. Langkah-langkah analisis data dalam penelitian ini, yaitu: (1) mengidentifikasi data, (2) mengklasifikasikan data dan memberi kode data, (3) menginterpretasi data berdasarkan maksim yang telah ditentukan, (4) menyimpulkan hasil analisis. Berdasarkan hasil penelitian, ditemukan pematuhan prinsip kesantunan berbahasa dalam diskusi ILC yakni maksim kebijaksanaan (buatlah kerugian penutur sekecil mungkin dan buatlah keuntungan penutur sebesar mungkin), maksim kedermawanan (penutur harus membut keuntungan diri sendiri sekecil mungkin dan membuat kerugian diri sebesar mungkin), maksim penghargaan (kecamlah orang lain sedikit mungkin; pujilah orang lain sebanyak mungkin), maksim kesederhanaan (pujilah diri sedikit mungkin; kecamlah diri sendiri sebanyak mungkin, maksim pemufakatan (peserta tutur dapat saling membina kecocokan di dalam bertutur), maksim kesimpatian (peserta tutur dapat memaksimalkan sikap simpati).
\end{abstract}

Kata Kunci: Kesantunan berbahasa, Prinsip Pematuhan, Maksim.

\begin{abstract}
The purpose of this study is to describe the obedience of language politeness principles based on maxim of wisdom, maxim of generosity, maxim of appreciation, maxim of simplicity, maxim of agreement, and maxim of sympathy. The method used in this research is descriptive method. Data collection techniques in this research are documentation techniques. The data in this study are speeches that contain politeness namely wisdom maxim, maxim of generosity, maxim of appreciation, maxim of simplicity, maxim of consensus, and maxim of sympathy in ILC discussion program on TV One was on March 9, 2019-26, March 2019. The steps of data analysis in this study, namely: (1) identifying data, (2) classifying data and coding data, (3) interpreting data based on predetermined maxims, (4) summarizing the results of the analysis. Based on the results of the study, it was found that the compliance with the principles of language politeness in the ILC discussion were maxim of wisdom (make the smallest possible loss of the speaker
\end{abstract}


and make the greatest possible profit of the speaker), maxim of generosity (the speaker must make the smallest possible self-benefit and make the greatest possible loss of self), the maxim of appreciation (condemn others as little as possible; praise others as much as possible), maxim of simplicity (praise yourself as little as possible; criticize yourself as much as possible, maxim of engagement (speech participants can foster mutual compatibility in speaking), maxim of sympathy (speech participants can maximize attitude sympathy)

Keywords: language civility, politeness principle, maxim

\title{
Abstrak
}

Tujuan penelitian ini untuk mendeskripsikan pematuhan prinsip kesantunan berbahasa berdasarkan maksim kebijaksanaan, maksim kedermawanan, maksim penghargaan, maksim kesederhanaan, maksim pemufakatan, dan maksim kesimpatian. Metode yang digunakan dalam penelitian ini adalah metode deskriptif. Teknik pengumpulan data dalam penelitin ini teknik dokumentasi. Data dalam penelitian ini adalah tuturan yang mengandung kesantunan berbahasa yakni maksim kebijaksanaan, maksim kedermawanan, maksim penghargaan, maksim kesederhanaan, maksim pemufakatan, dan maksim kesimpatian dalam acara diskusi ILC di TV One tayang pada tanggal 09 Maret 2019-26 maret 2019. Langkah-langkah analisis data dalam penelitian ini, yaitu: (1) mengidentifikasi data, (2) mengklasifikasikan data dan memberi kode data, (3) menginterpretasi data berdasarkan maksim yang telah ditentukan, (4) menyimpulkan hasil analisis. Berdasarkan hasil penelitian, ditemukan pematuhan prinsip kesantunan berbahasa dalam diskusi ILC yakni maksim kebijaksanaan (buatlah kerugian penutur sekecil mungkin dan buatlah keuntungan penutur sebesar mungkin), maksim kedermawanan (penutur harus membut keuntungan diri sendiri sekecil mungkin dan membuat kerugian diri sebesar mungkin), maksim penghargaan (kecamlah orang lain sedikit mungkin; pujilah orang lain sebanyak mungkin), maksim kesederhanaan (pujilah diri sedikit mungkin; kecamlah diri sendiri sebanyak mungkin, maksim pemufakatan (peserta tutur dapat saling membina kecocokan di dalam bertutur), maksim kesimpatian (peserta tutur dapat memaksimalkan sikap simpati).

\section{Kata Kunci: Kesantunan berbahasa, Prinsip Pematuhan, Maksim}

\begin{abstract}
The purpose of this study is to describe the obedience of language politeness principles based on maxim of wisdom, maxim of generosity, maxim of appreciation, maxim of simplicity, maxim of agreement, and maxim of sympathy. The method used in this research is descriptive method. Data collection techniques in this research are documentation techniques. The data in this study are speeches that contain politeness namely wisdom maxim, maxim of generosity, maxim of appreciation, maxim of simplicity, maxim of consensus, and maxim of sympathy in ILC discussion program on TV One was on March 9, 2019-26, March 2019. The steps of data analysis in this study, namely: (1) identifying data, (2) classifying data and coding data, (3) interpreting data based on predetermined maxims, (4) summarizing the results of the analysis. Based on the results of the study, it was found that the compliance with the principles of language politeness in the ILC discussion were maxim of wisdom (make the smallest possible loss of the speaker and make the greatest possible profit of the speaker), maxim of generosity (the speaker must make the smallest possible self-benefit and make the greatest possible
\end{abstract}


loss of self), the maxim of appreciation (condemn others as little as possible; praise others as much as possible), maxim of simplicity (praise yourself as little as possible; criticize yourself as much as possible, maxim of engagement (speech participants can foster mutual compatibility in speaking), maxim of sympathy (speech participants can maximize attitude sympathy)

Keywords: language civility, politeness principle, maxim

\section{PENDAHULUAN}

Bahasa merupakan alat komunikasi dan interaksi yang dimiliki oleh manusia untuk berhubungan dengan yang lain. Bahasa bagi mereka merupakan suatu media yang dapat dipakai untuk bersosialisasi. Bahasa di dalam masyarakat memiliki fungsi yang sangat luas. Menurut Chaer dan Agustina (2010: 14), fungsi bahasa adalah alat untuk berintraksi atau alat untuk berkomunikasi, dalam arti untuk menyampaikan pikiran, gagasan, konsep, dan juga perasaan.

Kesantunan berbahasa lebih berkenaan dengan bahasanya (Chaer, 2010:6). Kesantunan berbahasa sebenarnya merupakan cara yang ditempuh oleh penutur dalam berkomunikasi agar penutur tidak merasa tertekan, tersudut atau tersinggung (Markhamah, 2009: 153). Selanjutnya, menurut Moeliono dalam Sofyan Sauri, (2006: 51), kesantunan berbahasa berkaitan dengan tata bahasa dan pilihan bahasa, yaitu penutur bahasa menggunakan tata bahasa yang baku dan mampu memilih kata-kata yang sesuai dengan isi atau pesan yang disampaikan dan sesuai pula dengan tata nilai yang berlaku di masyarakat. Berdasarkan pendapat di atas dapat dikatakan bahwa kesantunan berbahasa adalah cara yang ditempuh oleh penutur dalam berkomunikasi dengan menggunakan tata cara bahasa dan tidak menggunakan bahasa kasar, menyinggung, menyudutkan serta mampu memilih kata-kata yang sesuai dengan isi pesan.

Pranowo (2009: 14) mengatakan bahasa santun adalah bahasa yang dapat mencerminkan perilaku penutur sebagai manusia yang berharkat dan bermartabat serta mampu menjadikan mitra tutur berkenaan dengan bahasa itu. Dalam hal ini, dengan berbahasa yang santun dalam bertutur diharapkan mampu untuk bertutur kata yang halus dan isi tutur memiliki maksud yang jelas, dapat menyejukkan hati, dan membuat orang lain berkenaan. Akan tetapi, ketika dalam berkomunikasi tidak memperhatikan kesantunan berbahasa dalam bertutur kerap kali akan menimbulkan berbagai masalah seperti memunculkan amarah lawan tutur, untuk itu kesantunan berbahasa penting dimiliki setiap individu dalam menjalin komunikasi di tengahtengah kehidupan bermasyarakat.

Chaer (2010: 10) mengatakan bahwa ada tiga kaidah yang harus dipatuhi agar tuturan kita terdengar santun oleh pendengar atau lawan tutur kita. Ketiga kaidah itu adalah (1) formalitas, (2) ketidaktegasan, dan (3) kesamaan atau kesekawanan. Pendapat ini dapat dikatakan bahwa sebuah tuturan disebut santun kalau ia tidak terdengar memaksa atau angkuh, tuturan itu memberi pilihan tindakan kepada lawan tutur, dan lawan tutur menjadi senang. Kesantunan berbahasa dapat dilakukan dengan cara pelaku tutur mematuhi prinsip sopan santun berbahasa yang berlaku di masyarakat pemakai bahasa itu. Jadi, diharapkan pelaku tutur dalam bertutur dengan mitra tuturya untuk tidak mengabaikan prinsip sopan santun. Hal ini untuk menjaga hubungan baik dengan mitra tuturnya.

Poedjosodarmo dalam Pranowo (2009: 36) mengatakan bahwa santun tidaknya pemakaian bahasa dapat diukur melalui tujuh prinsip, yaitu (1) kemampuan mengendalikan emosi agar tidak "lepas kontrol" dalam berbicara; (2) kemampuan memperlihatkan sikap bersahabat kepada mitra tutur; (3) gunakan kode bahasa yang mudah dipahami oleh mitra tutur; (4) kemampuan memilih topik yang disukai oleh mitra tuturdan cocok dengan situasi; (5) kemukakan tujuan pembicaraan dengan jelas, meskipun tidak harus seperti bahasa proposal; (6) penutur hendaknya memilih bentuk kalimatyang baik dan ucapkan dengan enak agar 
mudah dipahami dan diterima oleh mitra tutur dengan enak pula; (7) perhatikan norma lain, seperti gerakan tubuh (gestur), urutan tuturan.

Dalam kajian kesantunan berbahasa terdapat prinsip-prinsip kesantunan berbahasa yang dapat dijadikan acuan. Menurut Leech (1993: 166) mengatakan bahwasanya prinsipprinsip kesantunan dalam berbahasa terdapat beberapa golongan yaitu: (1) maksim kebijaksanaan, (2) maksim kedermawaan, (3) maksim penghargaan, (4) maksim kesederhanaan, (5) maksim pemufakatan, dan (6) maksim kesimpatian.

Dari beberapa teori di atas, penulis menyimpulkan untuk menggunakan teori Lecch dalam melakukan penelitian. Alasan penulis menggunakan teori Lecch, berdasarkan observasi awal yang dilakukan penulis, ditemukan bahwa pada acara ILC terdapat kesantunan berbahasa dengan prinsip kesantunan berbahasa dalam melaksanakan penelitian. Bersamaan dengan hal ini bahwa penggunaan teori Lecch sesuai dengan konteksnya dalam penelitian ini.

Kelebihan teori Leech ini yaitu penjelasanya sudah luas, karena Leech sudah mengembangkan kesantunan berbahasa dari teori-teori sebelumunya. Sedangkan kelemahan teori ini terletak pada rumitnya bagi penulis dalam mengidentifikasi dan mengelompokkan data tuturan yang mematuhi kesantunan berdasarkan enam maksim.

Dipilihnya ILC sebagai objek penelitian karena acara ILC ini menampilkan dialog pembawa acara dan narasumbernya yang menghadirkan diskusi di dalamnya. Dalam penelitian ini mengkaji tentang pematuhan prinsip kesantunan berbahasa, bagaimana pematuhan prinsip kesantuan berbahasa yang dilakukan peserta tutur dalam diskusi pada acara ILC tersebut. Mengingat bahwa acara ILC ini kerap menghadirkan para tokoh-tokoh yang berkualitas sesuai dengan profesinya.

Penelitian yang relevan ada enam dalam penelitian ini yaitu, penelitian yang dilakukan oleh Maulidi (2015) dengan judul penelitian "Kesantunan Berbahasa Pada Jejaring Sosial; Facebook", penelitian Dari (2016) dengan judul penelitian "Kesantunan Berbahasa pada Kegiatan Pembelajaran Kelas VIII E SMPN 2 Kota Bengkulu”, Penelitian Wahida (2016) dengan judul penelitian "Analisis Kesantunan Berbahasa Menurut Leech pada Tuturan Berbahasa Arab Guru Pondok Pesantren Ibnul Qoyyim Putra Yogyakarta”, Penelitian Sari (2014) dengan judul Penelitian "Analisis Kesantunan Berbahasa Berita Online; Pemberitaan Tentang Menteri Kelautan dan Perikanan, Susi Pudjiastuti”, Penelitian Cahyaningrum (2018) yang berjudul "Kesantunan Berbahasa Siswa Dalam Konteks Negosiasi Di Sekolah Menengah Atas", dan Penelitian yang dilakukan oleh Yudyati (2014) dengan judul penelitian "Kesantunan Berbahasa dalam Pembelajaran Berkomentar".

Keenam penelitian ini merupakan pijakan atau acuan bagi penulis dalam mengkaji penelitian yang dilakukan. Perbedaan penelitian terdahulu dengan penelitian yang dilakukan terletak pada objek kajiannya saja, sedangkan persamaannya yaitu, mengguankan prinsip kesantunan Lecch. Dalam prinsip kesantunan Lecch menggunakan enam maksim, yaitu maksim kebijaksanaan, maksim kedermawanan, maksim penghargaan, maksim kesederhanaan, maksim kemufakatan, dan maksim kesimpatian. Berdasarkan latar belakang yang sudah diuraikan, maka penulis tertarik untuk melakukan penelitian mengenai pematuhan perinsip kesantunan berbahasa dalam diskusi Indonesia lawyers Club dengan judul "Kesantunan Berbahasa dalam Diskusi pada Acara Indonesia Lawyers Club Di TV One".

\section{METODE}

Metode penelitian ini menggunakan metode penelitian deskriptif. Data dalam penelitian ini adalah tuturan yang mengandung kesantunan berbahasa yakni maksim kebijaksanaan, maksim kedermawanan, maksim penghargaan, maksim kesederhanaan, maksim pemufakatan, dan maksim kesimpatian dalam acara diskusi ILC di TV One tayang pada tanggal 09 Maret 2019-26 maret 2019. Langkah-langkah analisis data dalam penelitian ini adalah mengidentifikasi data, mengklasifikasikan data dan memberi kode data, 
menginterpretasi data berdasarkan maksim yang telah ditentukan, dan menyimpulkan hasil analisis.

\section{HASIL DAN PEMBAHASAN}

\section{HASIL}

Hasil penelitian yang ditemukan adalah bentuk pematuhan prinsip kesantunan berbahasa pada acara diskusi Indonesia Lawyers Club di Tv One. Berdasarkan data tuturan pematuhan prinsip kesantunan berbahasa pada acara diskusi Indonesia Lawyers Club di Tv One ditemukan 58 data tuturan mengandung enam maksim, yaitu maksim kebijaksanaan, maksim kedermawanan, maksim penghargaan, maksim kesederhanaan, maksim pemufakatan, dan maksim kesimpatian dengan menggunakan teori Lecch.

Pematuhan prinsip kesantunan berbahasa pada acara diskusi Indonesia Lawyers Club di Tv One ditemukan tuturan narasumber dengan pembawa acara, pembawa acara dengan narasumber, tuturan pembawa acara dengan narasumber dan pemirsa, tuturan narasumber dengan narasumber, tuturan narasumber dengan pemirsa, dan reporter ILC dengan narasumber.

\section{PEMBAHASAN}

\section{PEMATUHAN MAKSIM KEBIJAKSANAAN}

Leech (1993: 166) mengatakan maksim kebijaksanaan memiliki dua segi, yaitu segi negatif buatlah kerugian petutur sekecil mungkin', dan kedua, segi positif 'buatlah keuntungan petutur sebesar mungkin'.

Konteks

Penutur: Karni Ilyas (KI), Pembawa

acara

Mitra tutur : Neta S Pane (NSP) dan Rachland Nashidik (RN), narasumber

Hari/tanggal : Selasa, 05 Maret 2019, Pukul 20.00 WIB

Tempat: Studio Tv One

Situasi : Formal

Topik : Andi Arif Terjerat

Narkoba; Pukulan Bagi Kubu 02

NSP: Saya tidak mengatakan dia mendapatkan perlakuan khusus

$\mathbf{R N}$ : Anda mengatakan begitu anda bilang ewo pakewo, hubungan dengan Jen. Bintang tiga

NSP: Jadi gini kaitannya bahwa.....

RN : Diperbaiki kata-katanya, jangan terjadi......

NSP: Enggak, terjadinya kesemerautan sikap polisi terhadap kasus Andi Arif dalam pandangan saya ini karena ada faktor kedekatan. Kemudian...

RN : Itu pernyataan berbahaya kalau anda bilang perlakuan istimewa karena faktor kedekatan

KI: Itu pandangan dia, jadi anda juga nggak boleh dong melarang pandangan dia, silahkan

NSP: Ya, jadi kita berharap polisi profesional lah dalam menangani kasus Adi Arif jangan mau di interpensi siapapun. Sikap profesional Polri harus ditunjukan. Misalnya sama seperti pemakai narkoba setelah 
ditangkap rumahnyakan di geleda sampai sekarang belum ada tanda-tanda rumahnya Andi Arif akan di geleda harusnya di geleda. Rafi Ahmad kita tau rumahnya di geleda kemudian ditemukan adanya lintingan ganja disana. Jadi polisi harus bekerja cepat, tegas, sigap jangan belum apa-apa kemudian rehabilitasi orang kasusnya saja belum selesai kok, rumahnya belum di geleda, yang lain-lain belum di geleda.

Tuturan data di atas, KI sebagai penutur, NSP, dan RN sebgai mitra tutur. Penggunaan kata tuturan "Itu pandangan dia, jadi anda juga nggak boleh dong melarang pandangan dia" merupakan wujud pematuhan maksim kebijaksanaan. Tuturan KI mengandung pematuhan maksim kebijaksanaan maknanya adalah menghargai mitra tutur, mengetahui waktu yang tepat ketika berbicara, dan membuat keputusan yang tepat dan bijak. Tuturan KI di atas mematuhi maksim kebijaksanaan karena dalam tuturan itu memiliki tanda kesantunan yaitu penutur KI melarang mitra tuturnya RN berbicara atau berpendapat pada waktu NSP menyampaikan pendapatnya mengenai tema diskusi. Pemilihan kata seperti "Silahkan" menunjukkan penutur KI selaku pembawa acara atau pimpinan acara memberikan waktu sepenuhnya kepada NSP untuk melanjutkan kembali argumennya yang sempat disela oleh mitra tutur RN. Maksim kebijaksanaan yang dipatuhi oleh penutur yakni penutur tidak lalai selaku pimpinan acara pada diskusi tersebut sehingga bisa membuat acara diskusi itu berjalan dengan kondusif karena mitra tutur NSP dan RN sebelumnya terjadi perdebatan. Sikap penutur KI menandakan bahwa penutur KI mematuhi maksim kebijaksanaan.

Pada contoh tuturan penelitian sebelumnya dengan penelitian ini, ditemukan tuturan yang memiliki kesamaan yaitu, pematuhan maksim kebijaksanaan yang ditandai dengan ciri-ciri kesantunan berbahasa, yaitu menghargai mitra tutur, membuat keputusan tepat dan bijak, serta penutur bisa mencari celah untuk memecahkan masalah. Perbedaan penelitian terdahulu dengan penelitian ini adalah ada beberapa penelitian terdahulu yang tidak memiliki kesantunan pematuhan maksim kebijaksanaan karena konteks dan situasi yang mengarah pada ciri pematuhan maksim kebijaksanaan tidak ditemukan, ada penelitian terdahulu yang tidak menggunakan teori Lecch dalam menganalisis, dan objek kajian penelitian terdahulu dengan penelitian ini berbeda.

\section{PEMATUHAN MAKSIM KEDERMAWANAN}

Leech (1993: 209) mengatakan bahwa di dalam maksim kedermawanan penutur harus membuat keuntungan diri sendiri sekecil mungkin dan membuat kerugian diri sebesar mungkin.

Konteks

Penutur: Rachland Nashidik (RN), Narasumber

Mitra tutur : Karni Ilyas (KI), Pembawa Acara

Hari/tanggal : Selasa, 05 Maret 2019, Pukul 20.00 WIB

Tempat: Studio Tv One

Situasi : Formal

Topik : Andi Arif Terjerat

Narkoba; Pukulan Bagi Kubu 02

KI : Maksud Pak Rachland yang di langkat?

RN : Iya artinya korban dari narkoba

KI : Bandar itu ya di langkat

$\mathbf{R N}$ : Benar itu ada tiga, ada tiga kasus 
yang dalam waktu dekat saya kira pernah terjadi, kita ingat apa namanya ekstasi berapa klio lalu ada sabu, ada tiga partai kalau tidak salah soal, ada partai PKB, partai PDIP, dan Nasdem semuanya bandar gitu dan itu tidak mengundang perhatian begitu besar seperti perhatian yang diberikan malam ini dan malam-malam sebelumnya dan mungkin juga beberapa hari kedepan terhadap rekan saya saudara Andi Arief. Memang benar bahwa sebetulnya tidak ada hubungan yang apa namanya tidak ada hubungan antara sikap individual dengan kebijakan partai ini adalah masalah hukum dan dalam prinsip ini dalam kasus ini saya kira berlaku prinsip individual kriminal responbility itu prinsip pertanggungjawaban pidana secara individual dan dalam konteks itu kami sudah menyatakan dalam konfersipers tadi yang saya lakukan bahwa pihak keluarga telah menunjuk tim kuasa hukum yang terdiri dari lima pengacara, lima lawyers yang akan memberikan penjelasan-penjelasan kepada publik apabila diperlukan mengenai kasus saudara Andi Arief. Saya baru saja pulang dari menjenguk Andi Arief mudah-mudahan besok siang saya sudah bisa membawa Andi pulang dari tempatnya sekarang direktorat narkoba, tapi tadi saya bertemu dengan Andi meminta saya untuk menyampaikan dua hal, yang pertama adalah permintaan maafnya bukan saja kepada partai juga kepada publik di luar karena dia merasa telah mengecewakan banyak sekali orang dan dia menyesali itu.

Tuturan data di atas, RN sebagai penutur dan KI sebagai mitra tutur. Penggunaan kata tuturan "Saya baru saja pulang dari menjenguk Andi Arief mudah-mudahan besok siang saya sudah bisa membawa Andi pulang dari tempatnya sekarang direktorat narkoba dan Andi meminta saya untuk menyampaikan dua hal, yang pertama adalah permintaan maafnya bukan saja kepada partai, juga kepada publik di luar karena dia merasa telah mengecewakan banyak sekali orang dan dia menyesali itu" merupakan wujud pematuhan maksim kebijaksanaan. Tuturan RN mengandung pematuhan maksim kebijaksanaan maknanya adalah penutur menawarkan sesuatu bukan untuk dirinya sendiri dan penutur memberikan bantuan pada mitra tutur. Tuturan RN di atas mematuhi maksim kedermawanan karena memiliki tanda kesantunan yaitu penutur RN menyampaikan kepada seluruh narasumber dan pemirsa ILC bahwa Penutur RN berharap atas kejadian yang menimpa korban Andi arif bisa cepat selesai permasalahannya dan penutur RN juga mewakili korban Andi Arif untuk menyapaikan pesan permohonan maaf atas perbuatannya. Dalam kutipan tuturan di atas penutur RN dalam diskusi menyampaikan kesimpatiannya terhadap korban yaitu Andi Arif. Sikap penutur RN menandakan bahwa penutur RN mematuhi maksim kebijaksanaan.

Pada contoh tuturan penelitian sebelumnya dengan penelitian ini, ditemukan tuturan yang memiliki kesamaan yaitu, pematuhan maksim kedermawanan yang ditandai dengan ciri-ciri kesantunan berbahasa, yaitu memberikan bantuan kepada mitra tutur dan penutur menawarkan sesuatu bukan untuk dirinya sendiri. Perbedaan penelitian terdahulu dengan penelitian ini adalah ada beberapa penelitian terdahulu yang tidak memiliki kesantunan pematuhan maksim kebijaksanaan karena konteks dan situasi yang mengarah pada ciri pematuhan maksim kedermawanan tidak ditemukan, ada penelitian terdahulu yang tidak menggunakan teori Lecch dalam menganalisis, dan objek kajian penelitian terdahulu dengan penelitian ini berbeda.

\section{PEMATUHAN MAKSIM PENGHARGAAN}

Leech (1993: 211-212) mengatakan bahwa pada maksim penghargaan kecamlah orang lain sedikit mungkin; pujilah orang lain sebanyak mungkin.

Konteks

Penutur: Karni Ilyas (KI), Pembawa 


\begin{abstract}
Acara
Mitra tutur $\quad$ : Pemirsa ILC dan narasumber

Hari/tanggal : Selasa, 05 Maret 2019, Pukul 20.00 WIB

Tempat: Studio Tv One

Situasi : Formal

Topik : Andi Arif Terjerat

Narkoba; Pukulan Bagi Kubu 02

KI: Pemirsa, malam ini kita bertemu

kembali di Indonesia Lawyers Club

dengan tema diskusi malam ini "Andi Arief terjerat narkoba; pukulan bagi kubu 02". Sebelumnya, applause dulu untuk duet yang malam ini tampil Zean dan Eka Delly, dengan lagu yang berjudul "slow" kita taunya slow jadi kita selow. Pemirsa, banyak yang bertanya kenapa ini yang diangkat malam ini, kenapa tidak bawaslu misalnya atau KPU atau kenapa bukan cuti presiden yang dipersoalkan, macam-macam. Adalagi KTP, katanya WNA juga dapat KTP.

Tuturan data di atas, KI sebagai penutur, Pemirsa ILC dan Narasumber sebagai mitra tutur. Penggunaan kata tuturan "Sebelumnya, applause dulu untuk duet yang malam ini tampil Zean dan Eka Delly, dengan lagu yang berjudul "slow" kita taunya slow jadi kita selow" merupakan wujud pematuhan maksim penghargaan. Tuturan KI mengandung pematuhan maksim penghargaan maknanya adalah penutur menyampaikan hal menyenangkan atau pujian kepada mitra tutur. Tuturan KI di atas mematuhi maksim penghargaan karena memiliki tanda kesantunan yaitu penutur KI mengajak seluruh tamu undangan untuk memberikan apresiasi berupa tepuk tangan kepada Zean dan Eka Delly atas penampilannya yang telah memberikan hiburan sebelum acara dibuka. Sikap penutur KI menandakan bahwa penutur KI mematuhi maksim penghargaan.

Pada contoh tuturan penelitian sebelumnya dengan penelitian ini, ditemukan tuturan yang memiliki kesamaan yaitu, pematuhan maksim penghargaan yang ditandai dengan ciri-ciri kesantunan berbahasa, yaitu menyampaikan hal yang menyenangkan atau pujian kepada mitra tutur dan tidak menyinggung mitra tutur. Perbedaan penelitian terdahulu dengan penelitian ini adalah ada beberapa penelitian terdahulu yang tidak memiliki kesantunan pematuhan maksim penghargaan karena konteks dan situasi yang mengarah pada ciri maksim penghargaan tidak ditemukan, ada penelitian terdahulu yang tidak menggunakan teori Lecch dalam menganalisis, dan objek kajian penelitian terdahulu dengan penelitian ini berbeda.
\end{abstract}

\title{
PEMATUHAN MAKSIM KESEDERHANAAN
}

Leech (1993: 214-215) mengatakan bahwa pada maksim kesederhanaan atau kerendahan hati ini, pujilah diri sedikit mungkin; kecamlah diri sendiri sebanyak mungkin.

Konteks

Penutur: Benny Mamoto (BM), narasumber

Mitra tutur : Karni Ilyas (KI), Pembawa acara

Hari/tanggal $\quad$ : Selasa, Rabu, 05 Maret 2019, Pukul 20.00 WIB

Tempat: Studio Tv One

Situasi : Formal

Topik : Andi Arif Terjerat 
narkoba; Pukulan Bagi Kubu 02

KI: Pak Benny itu dari dulu uda punya

kecurigaan bahwa bakal sampai ada ungkapan dari Prof. Mahfud bahwa ini sudah sampai ke Istana dan bagaimana Pak Benny melihat sampai sekarang ini yang terjadi?

BM: Terima kasih Bang Karni, saya akan

mencoba menjelaskan sesuai kompetensi yang saya miliki. Saya akan memulai dengan mengutip, satu statement tentang pakar narkoba dari DIE namanya Steven Gasdil dia mengatakan begini narkoba adalah senjata perusak masal yang efektif untuk menghancurkan masyrakat. Kemudian kami akan masuk pada siapa sih yang bertanggung jawab? Permaslahan narkoba adalah permasalahan kita bersama.

Tuturan data di atas, BM sebagai penutur, KI sebagai mitra tutur. Penggunaan kata tuturan "Terima kasih Bang Karni, saya akan mencoba menjelaskan sesuai kompetensi yang saya miliki” merupakan wujud pematuhan maksim kesederhanaan. Tuturan BM mengandung pematuhan maksim kesederhanaan maknanya adalah mengurangi pujian dan tidak menonjolkan kelebihan pada diri sendiri dan tidak sombong. Tuturan BM di atas mematuhi maksim kesederhanaan karena memiliki tanda kesantunan yaitu penutur BM berusaha bersikap rendah hati dan mengurangi pujian terhadap dirinya sendiri dengan cara menyatakan bahwa dia akan mecoba menjelaskan dengan kemampuan yang dia miliki terhadap pertannyaan mitra tutur. Tuturan BM "Terima kasih Bang Karni” adalah bentuk tuturan penghargaan dan menghormati mitra tutur sebelum menjawaab pertanyaan. Sikap penutur BM menandakan bahwa penutur BM mematuhi maksim kesederhanaan.

Pada contoh tuturan penelitian sebelumnya dengan penelitian ini, ditemukan tuturan yang berbeda. Dalam penelitian terdahulu ada penelitian yang tidak ditemukan pematuhan maksim kesederhanaan karena konteks dan situasi yang terjadi tidak menimbulkan topik yang mengarah pada ciri pematuhan maksim kesederhanaan. Akan tetapi pada penelitian ini memiliki pematuhan maksim kesederhanaan yang ditandai dengan ciri-ciri kesantunan berbahasa, yaitu mengurangi pujian dan tidak menonjolkan kelebihan pada diri sendiri dan tidak sombong.

\section{PEMATUHAN MAKSIM PEMUFAKATAN}

Lecch (1993: 217-218) mengatakan maksim kesepakatan adalah orang cenderung melebih-lebihkan kesepakatannya dengan orang lain, dan juga mengurangi ketidaksepakatannya dengan orang lain, dan juga mengurangi kesepakataanya dengan ungkapan-ungkapan penyesalan, kesepakatan sebagian.

Konteks

Penutur: Karni Ilyas (KI), Pembawa

acara

Mitra tutur : Maman Imanulhaq (MI), narasumber

Hari/tanggal : Selasa, 05 Maret 2019, Pukul 20.00 WIB

Tempat: Studio Tv One

Situasi : Formal

Topik : Andi Arif Terjerat narkoba; Pukulan Bagi Kubu 02

MI: Assalamukalaikum Wr. Wb Bang Karni dan seluruh pemirsa ILC.

Point pertama kita harus sepakat dulu bahwa narkoba adalah musuh kita bersama sepakat semuanya ya?

KI: Semuanya setuju itu 
MI: Oke itu setuju. Kita lihat bahwa semua pejabat, artis, orang biasa, sudah terkena narkoba.

Tuturan data di atas, KI sebagai penutur, MI sebagai mitra tutur. Penggunaan kata tuturan "Semuanya setuju itu" merupakan wujud pematuhan maksim pemufakatan. Tuturan KI mengandung pematuhan maksim pemufakatan maknanya adalah menerima atau sepakat dengan mitra tutur. Tuturan KI di atas mematuhi maksim pemufakatan karena penutur KI menyetujui apa yang disampaikan oleh mitra tuturnya mengenai narkoba adalah musuh bersama. Sikap penutur KI menandakan bahwa penutur KI mematuhi maksim pemufakatan.

Pada contoh tuturan penelitian terdahulu dengan penelitian ini, ditemukan tuturan yang memiliki kesamaan, yaitu pematuhan maksim pemufakatan yang ditandai dengan ciri-ciri kesantunan berbahasa, yaitu menghargai pendapat mitra tutur, menerima atau sependapat dengan mitra tutur, dan menanggapi usulan dengan mitra tutur. Perbedaan penelitian terdahulu dengan penelitian ini yaitu ada bebrapa penelitian terdahulu yang tidak memiliki pematuhan kesantuan pemufakatan karena konteks dan situasi yang mengarah pada ciri maksim pemufakatan dan juga objek kajian dalam penelitian terdahulu dengan penelitian ini berbeda.

\section{PEMATUHAN MAKSIM KESIMPATIAN}

Di dalam maksim kesimpatian, diharapkan agar para peserta tutur dapat memaksimalkan sikap simpati antara pihak yang satu dengan pihak yang lainnya. Sikap antipati terhadap salah seorang peserta tutur akan dianggap sebagai tindakan tindak santun.

Konteks

Penutur: M. Efendi Gazali (MEG), narasumber

$\begin{array}{ll}\text { Mitra tutur } & \text { : Andi Arif } \\ \text { Hari/tanggal } & \text { : Selasa, 05 Maret 2019, } \\ & \text { Pukul 20.00 WIB } \\ \text { Tempat: Studio Tv One } \\ \begin{array}{ll}\text { Situasi } & \text { Formal } \\ \text { Topik } & \text { : Andi Arif Terjerat } \\ & \text { narkoba; Pukulan Bagi Kubu } 02\end{array}\end{array}$

MEG: Kembali ke judul ini pukulan bagi siapa maka dengan agak cepat tentunya kita harus melihat basis pendekatn yang kita pakai apa? Yang pasti kalau secara sederhana mengatakan sesudah ini Bang Andi Arif, salam juga ya bagi Bang Andi Arif mudah-mudahan sebagai dalam tanda petik korban ya cepatlah bisa terhabilitasi dan kembali seperti aktivis sedia kala

Tuturan data di atas, MEG sebagai penutur, Andi Arif sebagai mitra tutur. Penggunaan kata tuturan "Salam juga ya bagi Bang Andi Arif mudah-mudahan sebagai dalam tanda petik korban ya cepatlah bisa terhabilitasi dan kembali seperti aktivis sedia kala" merupakan wujud pematuhan maksim kesimpatian. Tuturan MEG mengandung pematuhan maksim kesimpatian maknanya adalah memberikan dukungan kepada mitra tutur. Tuturan MEG di atas mematuhi maksim kesimpatian karena penutur MEG menunjukan sikap simpati atas kejadian yang menipa Andi Arif. Tuturan ini memperlihatkan sikap simpati, memberikan dukungan, dan ketabahan kepada Andi Arif yang menjadi korban narkoba. Sikap penutur MEG menandakan bahwa penutur MEG mematuhi maksim kesimpatian.

Perbandingan penelitian terdahulu dengan penelitian yang dilakukan terdapat persamaan dengan penelitian terdahulu, yaitu sama-sama menggunakan teori Leech dalam menganalisis, hanya saja dalam penelitian ini objek kajiannya yang berbeda dengan penelitian terdahulu. Dalam penelitian ini objek penelitiannya yaitu pematuhan prinsip kesantunan 
berbahasa yang digunakan dalam diskusi ILC yang memperlihatkan bentuk tuturan pembawa acara dengan narasumber, narasumber dengan pembawa acara, pembawa acara dengan pemirsa, narasumber dengan narasumber, narasumber dengan pemirsa, dan reporter dengan narasumber. Dalam penelitian ini hanya membahas pematuhan prinsip kesantunan berbahasa saja, berbeda dengan penelitian terdahulu yang membahas pelanggarannya juga. Dapat disimpulkan dalam penelitian ini hanya meneruskan penelitian terdahulu.

\section{PENUTUP \\ KESIMPULAN}

Berdasarkan hasil penelitian, ditemukan pematuhan prinsip kesantunan berbahasa dalam diskusi ILC yakni maksim kebijaksanaan (buatlah kerugian penutur sekecil mungkin dan buatlah keuntungan penutur sebesar mungkin), maksim kedermawanan (penutur harus membut keuntungan diri sendiri sekecil mungkin dan membuat kerugian diri sebesar mungkin), maksim penghargaan (kecamlah orang lain sedikit mungkin; pujilah orang lain sebanyak mungkin), maksim kesederhanaan (pujilah diri sedikit mungkin; kecamlah diri sendiri sebanyak mungkin, maksim pemufakatan (peserta tutur dapat saling membina kecocokan di dalam bertutur), maksim kesimpatian (peserta tutur dapat memaksimalkan sikap simpati).

\section{SARAN}

Penulis mengharapkan terdapat penelitian selanjutnya mengenai kesantunan berbahasa, seperti pada acara Mata Nadjwa, Kick Andy, maupun di televisi lainnya seperti, METRO TV, TV ONE, dan NET TV, sehingga dapat ditemukan pematuhan kesantunan berbahasa dan pelanggaran kesantunan berbahasa yang berbeda dari acara diskusi ILC di Tv One.

\section{DAFTAR PUSTAKA}

Cahyaningrum, Fitria. 2018. Kesantunan Berbahasa Siswa dalam Konteks Negosiasi di Sekolah Menengah Pertama. Surakarta. Universitas Sebelas Maret.

Chaer, Abdul. 2010. Kesantunan Berbahasa. Jakarta: Rineka Cipta.

Chaer, Abdul dan Leonie Agustina. 2010. Sosiolinguistik Perkenalan Awal. Jakarta: Rineka Cipta.

Dari, Ayu Wulan. 2016. Kesantunan Berbahasa pada Kegiatan Pembelajaran Kelas VIII E SMPN 2 Kota Bengkulu. Universitas Bengkulu.

Leech, Geoffrey. 1993. Prinsip-Prinsip Pragmatik. Jakarta: Universitas Indonesia. Terjemahan M. D. D. Oka. 1983. The Principles Of Pragmatics. London: Longman Group UK.

Markhama, dkk. 2009. Analisis Kesalahan dan kesantunan Berbahasa. Surakarta: muhammadiyah Universitas Press.

Maulidi. 2015. Kesantunan Berbahasa pada Jejaring Sosial; Facebook. Universitas Tadulako.

Pranowo. 2009. Berbahasa Secara Santun. Yogyakarta: Pustaka Pelajar.

Pranowo. 2009. Kesantunan Berbahasa Tokoh Masyarakat Ditinjau dari Aspek Pragmatik. Yogyakarta: Universitas Sanata Dharma.

Rahardi, Kujana. 2005. Pragmatik Kesantunan Imperatif Bahasa Indonesia. Jakarta: Erlangga.

Saori, Sofyan. 2006. Pendidikan Berbahasa Santun. Bandung: PT Genesindo.

Sari, Scorpio Puspita. 2014. Analisis Kesantunan Berbahasa Berita On-Line: Pemberitaan Tentang Menteri Kelautan Dan Perikanan, Susi Pudjiastuti. Yogyakarta. Universitas Sebelas Maret.

Wahida, Yeni Lailatul. 2016. Analisis Kesantunan Berbahasa Menurut Leech pada Tuturan Berbahasa Arab Guru Pondok Pesantren Ibnul Qoyyim Putra Yogyakarta. UIN Sunan Kalijaga Yogyakarta. 
Diansyah Ramadhan, Ngudining Rahayu, Bambang Djunaidi

Yudyati, Rindy Loryta. 2014. Kesantunan Berbahasa dalam Pembelajaran Berkomentar. Universitas Muhamadiyah Surakarta 